\title{
Economics, QoS, and Charging in the Next Great Telecom Revolution
}

\author{
Andrew Odlyzko \\ University of Minnesota, USA \\ odlyzko@umn.edu
}

\begin{abstract}
While the Internet has attracted the bulk of the attention from the public as well as from researchers, the growth of wireless has had a far larger impact on the world, as measured by the number of users, the revenues, or the profits. Technology is leading to a convergence of the two areas, and this will be the next great telecom revolution. The relation between technological progress and consumer demand differs greatly in wireless from what continues to prevail on the wireline Internet, and this is leading to a reconsideration of some of the QoS and charging schemes that failed to find acceptance in the past. A perspective will be presented on what approaches are most likely to succeed, and why.
\end{abstract}

